\title{
84
}

\section{STILE: the growth of a flexible, interdisciplinary resource base for open learning}

\author{
Clive Ruggles \\ Leicester University \\ United Kingdom
}

\begin{abstract}
The STILE (The Students' and Teachers' Integrated Learning Environment) project is combining a commitment to open and flexible learning with an innovative technical approach to provide a flexible, interdisciplinary, continually growing resource base for student centred learning across the curriculum in higher education. Working initially at four UK universities it has developed a simple yet very powerful abstract model which enables both students and tutors efficiently to locate and access resources relevant to their current needs. Formative evaluation is taking place in departments representing a wide range of subject disciplines at the four sites. This paper describes STILE's approach, the abstract model and the implementation of the project so far, drawing particular attention to some of the pedagogical, technical and general issues which have been raised.
\end{abstract}

Main conference themes: resources, flexible learning, learner centred, learning

Educational areas: higher education

Study topics:

Secondary keywords: information retrieval, interdisciplinary, multimedia, open learning, open systems 


\section{THE STILE APPROACH}

Seventy-six projects sponsored by the UK Government's Teaching and Learning Technology Programme (TLTP) initiative, currently in its third year, are aiming to improve both the quality and efficiency of student learning $[1,2]$. The majority are run by subject consortia with the aim to produce interactive courseware in a given discipline area. Others are institutional projects with the aim to address problems of implementation within single institutions. STILE is one of very few TLTP projects concerned with ensuring easy access to and flexible use of learning resources [3, 4]. This approach stems from the belief that TLTP will only avoid the notorious lack of take-up of the products of similar initiatives in the past by ensuring that people are able to discover, in an open context, the existence of available resources (which may include items of courseware) which are directly relevant to their teaching or learning needs at a particular time, from within the plethora of materials which is rapidly becoming available particularly over the Internet.

The general way in which we picture users, resources and methods by which users access those resources, is illustrated in Figure 1. A key feature lies in the distinction between information about teaching and learning resources, and the materials themselves. The actual materials might be, for example, documents, databases, interactive courseware or simulations. While many of these might be IT based and deliverable then and there on line, this is by no means essential: the important thing is to identify the resource and describe how it can be accessed, whether on the one hand it is an on-line image database or on the other hand a book in the (conventional) library.

\begin{tabular}{|l|l|l|}
\hline Users & \multicolumn{1}{|c|}{ Access } & \multicolumn{1}{c|}{ Resources } \\
$\begin{array}{l}\text { Teachers as } \\
\text { resource providers } \\
\text { Students as } \\
\text { resource users }\end{array}$ & $\begin{array}{l}\text { Information abou } \\
\text { available resources } \\
\text { courseware }\end{array}$ \\
$\begin{array}{l}\text { Teachers as } \\
\text { resource users }\end{array}$ & $\begin{array}{l}\text { Topic (concept }) \\
\text { searching }\end{array}$ & $\begin{array}{l}\text { Simulations, etc. } \\
\text { Databases, i.e. } \\
\text { structured materials } \\
\text { Students as } \\
\text { resource providers }\end{array}$ \\
\cline { 2 - 3 } & $\begin{array}{l}\text { User develops own view } \\
\text { of relationship between } \\
\text { concepts and materials }\end{array}$ & $\begin{array}{l}\text { Rawt-based materials, } \\
\text { image-based } \\
\text { materials, etc. }\end{array}$ \\
\hline
\end{tabular}

Fig. 1 The STILE model of users, resources and the methods by which users access those resources 
The STILE approach enables all users to access and add to the resource information base in a way which is based upon their own views of relationships between topics and materials [5]. One advantage of this is that as a result it supports the widest possible range of pedagogical styles. Thus, in a wholly tutor led approach a teacher might act as resource provider and students would simply navigate and access the resources provided by that tutor. However, students who at a given time simply wish to know more about some topic, will often derive considerable benefit from the ability to discover resources for themselves within a much wider, open resource base. (Our experience to date indicates that resources will be used surprisingly often by tutors/students in completely different discipline areas.) More open approaches are permitted when we cease to restrict our view to teachers as resource providers and students as resource users. Teachers can derive considerable efficiency and quality gains by discovering the existence of resources produced elsewhere which are relevant to their current teaching needs, so that they can structure these according their own aims and methods for example by 'picking and mixing' from pieces of existing courseware or resources (Whether they are able directly to modify existing materials will of course depend upon the privileges and rights granted by the copyright holder). Furthermore, students can structure learning materials for themselves, annotate existing resources and even add their own resources.

The second advantage is that personal, topic (or concept) based indexing frees students from the need to be familiar with classification systems or keywords as in a conventional cataloguing system. This means that very little training is required. It also allows irrelevant words or phrases-for example, those mentioned merely in passing or in a negative sense, or homonyms referring in a given instance to a completely different topic - to be ignored .[5]

Perhaps the most important feature of the resource information base is that it will never be a closed and finished product. Rather, it is continually growing, from a departmental to a university, and now to an interuniversity level.

\section{THE ABSTRACT MODEL}

STILE systems are implementations of a high-level (logical) model which provides a simple yet powerful and flexible way of developing and organizing knowledge resources, easily understood by the user yet precisely (and formally) specified so as to enable suitable software tools to be developed quickly. Having such a model facilitates flexible use and provides a high degree of robustness against future developments. The formal model for STILE is based upon recent developments in distributed metadata system design $[6,7]$. 
Figure 2 gives a visualization of the STILE environment as perceived by an individual user on an abstract (logical) level. The shaded part comprises a set of topics, each of which encapsulates some theme or idea of interest to the user such as 'The Maya', 'Mayan ceremonial centres', 'Marxism' or 'Mesoamerica'. The term 'topic' is used in preference to the term 'concept' as it is not restricted to classes or categories, i.e. 'universal concepts' in the Popperian sense. Topics comprise nuggets of information (pieces of text, images, etc.) which 'explain' the topic to a user, together with links to other topics and to actual resources.

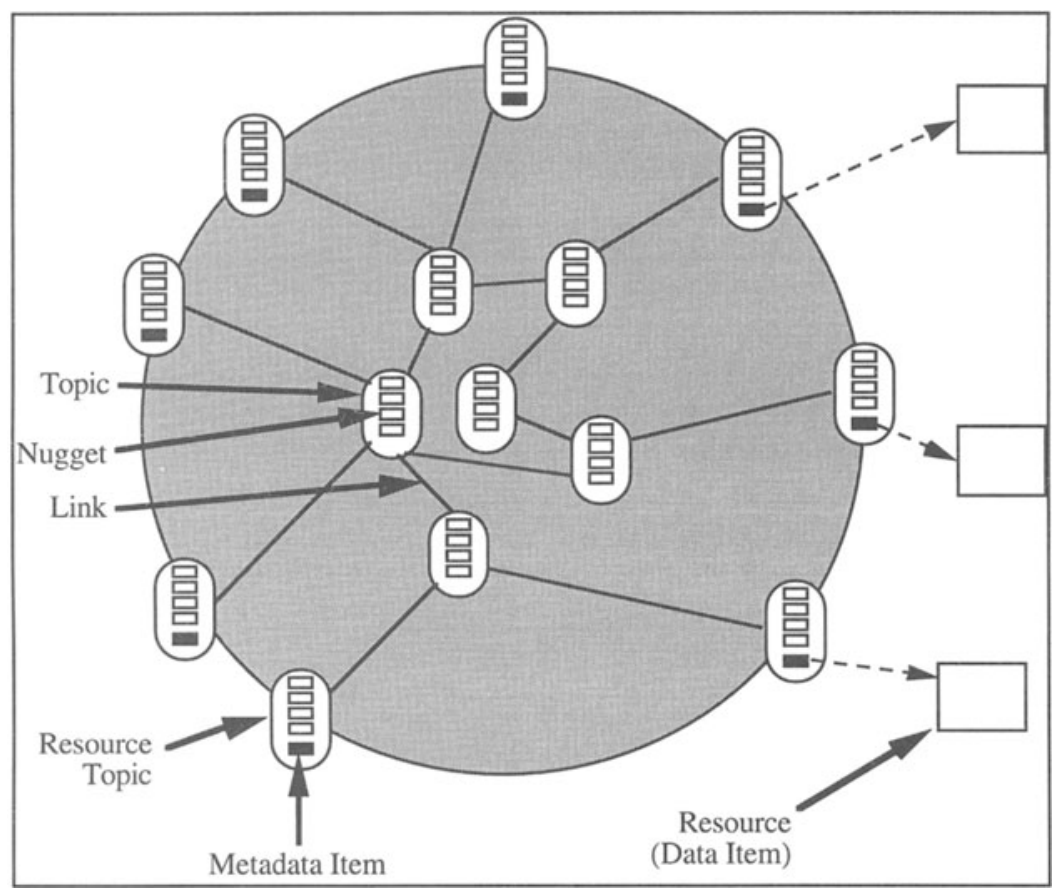

Fig. 2 The STILE environment as perceived by an individual user

The fact that links are untyped prevents, for example, a user introducing explicit hierarchical structuring. However, this has not proved a problem in practice and indeed there are strong pedagogical reasons for wishing to discourage this [8]. In addition it simplifies the structure considerably and enables efficient information retrieval to be achieved by such means as taking account of the context of an enquiry, i.e. knowledge which the system has 
about the enquirer at that point and which can prevent them being presented with data they are unlikely to be interested in at the time [7].

All users, student or teacher alike, may build their own topic net and link it through to nets established by other people. A student, for example, might choose (or be allowed) simply to navigate the nets set up by the tutors or might set up own topics pointing directly at a range of other relevant topics. However tutors might choose to link certain topics of their own to equivalent topics of another user, quite possibly in another Department or University, whom the tutor considers to have more useful information on a given topic.

Such a model has two main advantages. First, there is no need to define 'correct' terms for referring to things. Instead, each human user is free to develop an own set of terms for communicating topics to the own node. Second, the system provides a framework for each user to develop own world views covering both own topics and those communicated by other people. There is no need for this to be consistent with the world views of others.

\section{IMPLEMENTATION AND PROGRESS}

A number of implementations of the STILE model has been produced as the project has progressed using widely available public domain software wherever possible. Currently two STILE systems are in active use with students and teachers: a full system based upon a search engine developed within the Midlands Regional Research Laboratory $[9,10]$ and a highly deliverable, but lower functionality system where topics are implemented as sets of HTML documents distributed over the Internet, created and edited using special tools and accessible using the World Wide Web (WWW).

A STILE metalanguage (SML) has been developed to express instantiations of the high-level model and hence to provide a common metafile format for transfer between different versions (implementations) of the system and for data import from and export to other systems. A markup scheme or 'trivial metalanguage' (TML) provides a simple way for users to prepare materials in bulk using, for example, a conventional word processor or database management system and then import the materials via SML into a STILE implementation.

The establishment of an adequate resource base in the early stages has been achieved by working with a small number of 'Lead Departments' and steady growth is being achieved through a propagation mechanism in which Departments using the system act as mentors to other Departments, generally with overlapping interests, with whom they are twinned for a period of a few months. Some staff have made available multimedia resource bases, others 
have put up extensive bibliographic resource sets and still others are getting their students to use STILE to access on-line course organization materials (course information, booklists, worksheets etc.) which can then be updated while the course is running. Very quickly staff started to move beyond their initial ways of using the system, for example by supplementing bibliographic resource bases with on-line image materials.

STILE also provides a means of integrating these initially disparate resource bases into a much wider, integrated resource base which enables students and teachers to discover materials of relevance from outside their immediate environment. This has already begun to happen. For example, part of a database on the development of the atomic bomb developed by a History Department has proved of interest and use within a Physics Department.

In addition across-the-board course module and booklist information for Leicester and De Montfort Universities has been mounted on STILE, with similar information being promised for Loughborough University when it becomes available in the run-up to modularization in 1995/96. The aim is to provide an entry point to STILE for users in Departments other than those working directly with the project and hence to encourage further and wider development of the resource base than can be directly supported by the project. STILE is entering a high visibility phase at these sites: at Leicester, for example, it will be directly accessible from the University's WWW home page, alongside the campus wide information system (CWIS) with whom it is working in close collaboration.

Finally a team at the Open University is focusing on the use of STILE in a distance learning context. This opens up the possibility of students in remote locations being able to access an open information base using their home computer and modem, an opportunity which had hitherto been denied to them.

\section{ISSUES RAISED BY STILE}

One of the most important issues is to what extent information within STILE should be moderated. The STILE resource information base is inherently federal and open, and it would be possible to adopt the attitude that no moderation should take place, each user relying upon other users whom they trust to direct them towards reliable information [11]. In practice Departments working with STILE have been responsible for the content of their materials and are responsible for subject based peer review of these materials. The STILE project team has been providing guidance on the structuring of these materials. It is the view of the team that educational quality assurance should be achieved by undergoing an iterative process with an increasingly large base 
of users: reactions of staff and student users (through student forms) are an integral part of this process.

Technical quality control is necessary with current systems, for example to preserve referential integrity when topics are deleted or updated by fresh bulk import. Work is in progress to minimize the degree of technical quality control needed in later system implementations.

The problem of copyright is not as critical for STILE as for resource producers and distributors, since while students and lecturers will certainly wish to retain ownership of their own materials and may wish to restrict access to them, they are usually willing to give free access to information about those materials (Indeed, industrial metadata systems help to advertise materials which are being sold commercially by making a wider audience aware of them). Nonetheless, there is still a range of issues concerning copyright and intellectual property rights. For example, could someone be held responsible by the owner of a resource for including false information about that resource in their topic net?

At the moment one of the issues of central concern to TLTP as a is that of dissemination: how to get information about teaching and learning resources to the people who need it, when they need it. Indeed, the lack of such dissemination is one of the reasons why in the past computer based materials have not been taken up. STILE as one of the TLTP projects explicitly concerned with dissemination, appears to have a wider role within the initiative as a whole as its resource base expands. And it is one that is just beginning to be explored.

\section{REFERENCES}

1. Darby, J. (ed.) (1993) Teaching and Learning Projects. The CTISS File, 15, pp. 27-70.

2. Darby, J. (1993) Teaching and Learning Technology Programme: Phase II. The CTISS File, 16, pp. 6-7.

3. Walker, D.R.F. (1994) Flexible learning and information technology: the STILE Project. The CTISS File, 17, pp. 41-42.

4. Underwood, J.D. and Fitzpatrick, S. (1994) Focusing on resource-based learning: the STILE Project, in Deciding our Future: Technological Imperatives for Education (eds. Thomas, M., Sechrest, T. and Estes, N.), Austin, pp. 10141016. 
5. Ruggles, C.L.N. (1994) An integrated environment for open learning: the STILE approach, in Deciding our Future: Technological Imperatives for Education (eds.) Thomas, M., Sechrest, T. and Estes, N., Austin, pp. 419-421.

6. Madsen, M.S., Fogg, I.S. and Ruggles, C.L.N. (1994) Metadata systems: integrative technologies for utilisation of knowledge and resources. Libri, 44 (3) pp. 237-257.

7. Madsen, M.S., Fogg, I.S. and Ruggles, C.L.N. (1994) Meta-information systems: a design study. Australian Journal of Information Systems, 2 (1) pp. $39-51$.

8. Underwood, J.D. (1994) New directions in education: key concepts and issues relating to machine-mediated learning. In press.

9. Ruggles, C.L.N., Newman, I.A., Medyckyj-Scott, D.J. and Walker, D.R.F. (1992) Structuring spatially related meta-information for effective entry and retrieval. Computer Journal, 35, pp. A475-A486.

10. Walker, D.R.F., Newman, I.A., Mather, P., Ruggles, C.L.N. and Medyckyj-Scott, D.J. (1993) Federal network-based meta-information and central metadata management, in Statistical Metainformation Systems, Office for Official Publications of the European Communities, Luxembourg, pp. 233245 .

11. Fogg, I.S., Ruggles, C.L.N. and Newman, I.A. (1993) $A$ distributed metadata system. Research Report No. 34, Midlands Regional Research Laboratory, University of Leicester and Loughborough University. 